\title{
SLC20A2-Associated Idiopathic Basal Ganglia Calcification-Related Recurrent Psychosis Response to Low-Dose Antipsychotics: A Case Report and Literature Review
}

\author{
Akito Uno ${ }^{1}$, Hidetaka Tamune ${ }^{2}$, Hisaka Kurita ${ }^{3}$, Isao Hozumi ${ }^{3}$, Naoki Yamamoto ${ }^{1}$ \\ 1. Department of Neuropsychiatry, Tokyo Metropolitan Tama Medical Center, Tokyo, JPN 2. Department of \\ Neuropsychiatry, Graduate School of Medicine, The University of Tokyo, Tokyo, JPN 3. Neurology, Gifu Pharmaceutical \\ University, Gifu, JPN
}

Corresponding author: Hidetaka Tamune, tamune-tky@umin.ac.jp

\begin{abstract}
Idiopathic basal ganglia calcification (IBGC), also known as Fahr's disease or primary familial brain calcification, manifests as bilaterally symmetric calcifications in the brain. Clinical symptoms range from movement disorders to cognitive impairment and psychiatric symptoms. Since 2012, IBGC has been reported as an inherited disorder with several causative genes, including SLC20A2; however, the genotypephenotype association remains unclear. Furthermore, longitudinal follow-up studies investigating the prognosis of neuropsychiatric symptoms in IBGC are lacking.
\end{abstract}

A 36-year-old woman who experienced recurrent psychosis since the age of 30 years was admitted to our hospital. Her symptoms included delusions, hallucinations, disorganized speech, and grossly disorganized behavior. Cranial CT revealed calcification of the bilateral basal ganglia and dentate nucleus. The possibility of metabolic or endocrinological disorders causing secondary calcification was excluded via laboratory examinations. The genetic analysis revealed SLC2OA2 mutation, and therefore, she was diagnosed with definite IBGC. At the age of 37,42 , and 43 years, similar psychosis recurred due to a decrease in medication. Each episode was relieved within one week with a low dose of risperidone (1.5-2 mg/day p.o.). Eventually, remission was maintained with risperidone ( $1.5 \mathrm{mg} /$ day).

To our knowledge, genetically confirmed case of IBGC with psychosis has been rarely reported. Recurrent psychosis can be the sole symptom of SLC20A2-associated IBGC and may be remitted with a low dose of risperidone. Literature review including eight case reports shows no superiority between medications. Although our case indicates that a low dose of antipsychotics can alleviate symptoms without any side effects and should be continued to prevent relapse in some patients with IBGC, there has been still shortage of the clinical evidence. Further longitudinal studies on genotype-phenotype associations may expedite personalized medicine for patients with IBGC.

Review began 09/28/2020 Review ended 12/20/2020 Published 12/31/2020

\section{() Copyright 2020}

Uno et al. This is an open access article distributed under the terms of the Creative Commons Attribution License CC-BY 4.0., which permits unrestricted use, distribution, and reproduction in any medium, provided the original author and source are credited.
Categories: Genetics, Neurology, Psychiatry

Keywords: idiopathic basal ganglia calcification (ibgc), fahr's disease, antipsychotics, primary familial brain calcification (pfbc), risperidone, slc20a2, genotype-phenotype association, recurrent psychosis

\section{Introduction}

Idiopathic basal ganglia calcification (IBGC), also known as Fahr's disease or primary familial brain calcification, causes bilaterally symmetric calcifications in the brain, including the basal ganglia, dentate nucleus of cerebellum, thalamus, cerebral cortical gyrus, and deep cerebral white matter. Clinical manifestations range from motor symptoms to cognitive impairment and psychiatric symptoms. Exclusion of secondary factors such as endocrine disorders is necessary for diagnosis [1].

The pathophysiology of IBGC is mostly unknown, and the treatment is symptom-based. Although antipsychotics are used for treating psychosis, there is no standard regarding medication for psychosis in patients with IBGC. Causal genes for IBGC, such as SLC2OA2, PDGFRB, PDGFB, XPR1, MYORG, and JAM2, have been reported since 2012 [2-7]; however, genotype-phenotype associations have not been elucidated. Additionally, there are limited reports on the psychiatric symptoms of patients with IBGC, especially with longitudinal clinical courses.

Here, we report a case of $S L C 20 A 2$-associated IBGC with recurrent psychosis as the sole symptom in the 10year observation period, which was treated with a low dose of risperidone.

\section{Case Presentation}

A 36-year-old woman was admitted to our hospital because of acute psychosis. She had no previous physical 
or family history, except that her father had mild cognitive impairment. Her mother had noticed the patient's transient bizarre behavior since she was 30 years old, including attempts to grasp empty space claiming, "I can collect the holy spirit." One day before the first admission, she was in hallucinatorydelusional and psychomotor excitement states without daily fluctuation. On admission, she was treated with risperidone ( $2 \mathrm{mg} /$ day p.o.) under the tentative diagnosis of schizophrenia based on Diagnostic and Statistical Manual of Mental Disorders, Fourth Edition, Text Revision (DSM-IV-TR). The hallucinatorydelusional symptoms improved remarkably within a few days. No apparent cognitive impairments, extrapyramidal symptoms, or cerebellar ataxic symptoms were observed throughout the admission; therefore, we excluded comorbid movement disorders.

Cranial CT revealed prominent calcification of the bilateral basal ganglia and cerebellar dentate nuclei (Figure 1). The laboratory examination data revealed that blood $\mathrm{Ca}^{2+}$, inorganic phosphorus (Pi), alkaline phosphatase, parathyroid hormone, somatomedin C, and insulin-like growth factor-binding protein3 concentrations were all within the normal range. Hence, the possibility of metabolic or endocrinological disorders causing secondary calcification was ruled out.

Genetic analysis revealed a heterozygous SLC20A2 missense mutation (c.1487G > A, p.C496Y in exon 8) located at chromosome 8p11.21, which we published with its functional assessment elsewhere [8], confirming the clinical diagnosis of IBGC. The patient was discharged from the hospital within one month. After eight months, she arbitrarily terminated the medication and regular outpatient visits. After an additional five months, at the age of 37 , she was involuntarily hospitalized as her psychosis returned three days prior to admission. The symptoms were relieved with risperidone ( $2 \mathrm{mg} /$ day) after several days. She was discharged after one month and was maintained on risperidone (1 mg/day).

At the age of 42 , her risperidone dose was decreased from $1 \mathrm{mg} /$ day to $0.5 \mathrm{mg} /$ day at her own discretion. After one month, she was involuntarily hospitalized due to disorganized behaviors such as suddenly taking off her mother's dress; however, her symptoms improved within two days after increasing risperidone (1 mg/day), and she was discharged after two weeks. Later, the risperidone dose was increased to $1.5 \mathrm{mg} / \mathrm{day}$, which relieved her anxiety during her hospital visits.

At the age of 43, two months after the risperidone dose was reduced to $1 \mathrm{mg} /$ day on the patient's request, she noticed signs of relapse and was voluntarily admitted to the hospital. The risperidone dose was increased to $1.5 \mathrm{mg} /$ day, in which she recovered after a few days and was discharged after three weeks. During and after the hospitalization, her cognitive function was intact as her Mini-Mental State Examination (MMSE) score ranged from 28/30 to 30/30. Functional brain imaging with single-photon emission computed tomography (SPECT) and dopamine transporter (DAT) revealed no obvious signs of Parkinson's disease or related disorders.

Further, with shared decision-making on requirement for maintenance treatment, she has remained on the same prescription ( $1.5 \mathrm{mg}$ /day risperidone) with no relapse up to now (over four years). On clinical examination, no neurological findings including extrapyramidal or cerebellar symptoms, nor mood disorders, were noted for 10 years. Follow-up cranial CT revealed gradual but non-significant increases in the calcification of the bilateral basal ganglia and cerebellar dentate nucleus; the total calcification score [9] changed from 18 at 37 years to 20 at 47 years (Figure 1). 


\section{Cureus}
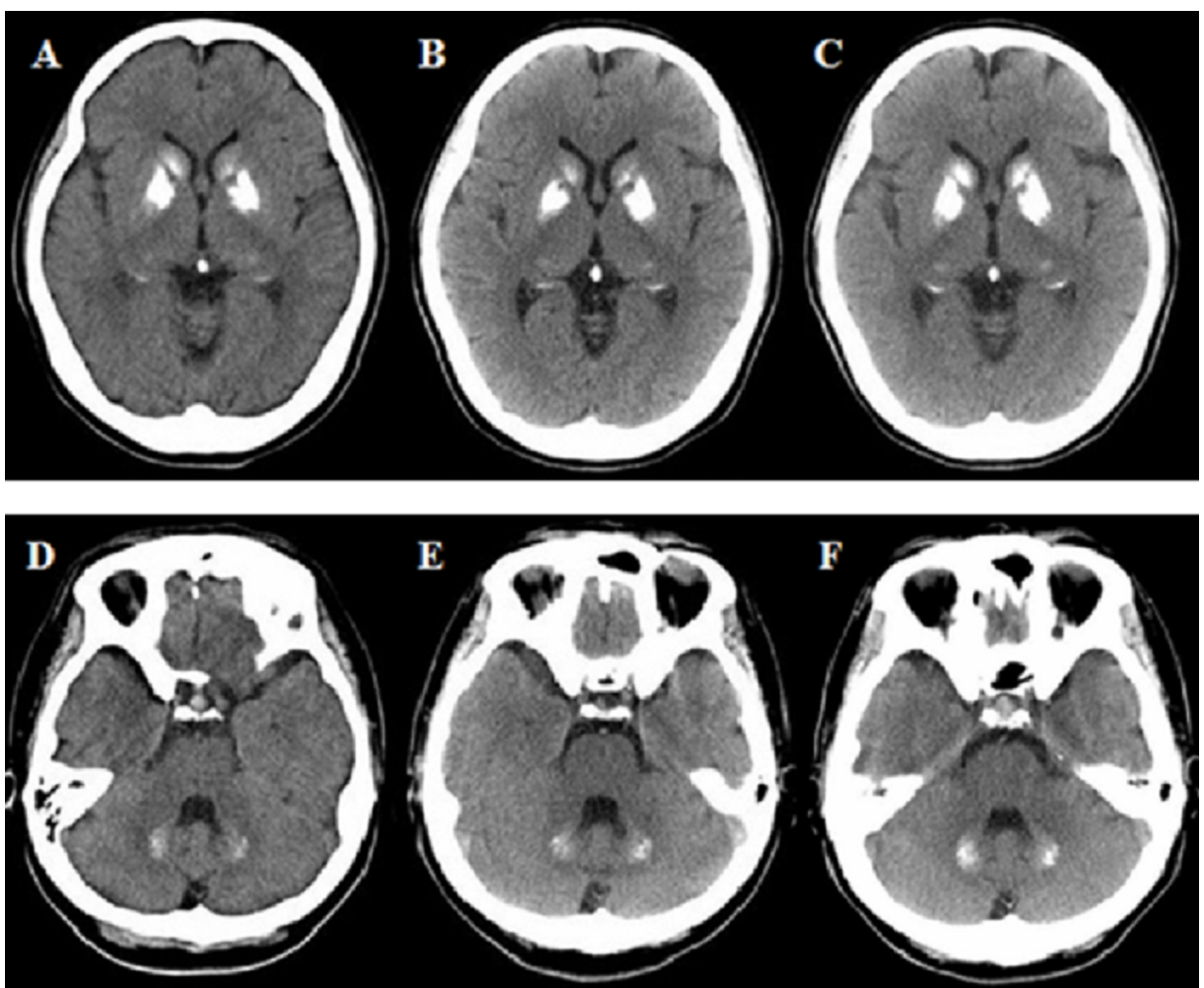

FIGURE 1: Longitudinal follow-up of the brain calcification in cranial CT

Basal ganglia at the age of 37 years (A), 43 years (B), and 47 years (C); cerebellar dentate nuclei at the age of 37 years $(D), 43$ years $(E)$, and 47 years $(F)$.

\section{Discussion}

To the best of our knowledge, genetically confirmed IBGC case presenting only as recurrent psychosis has been rarely reported, and we have reported its longitudinal clinical course with a 10-year follow-up period. This case indicates that recurrent psychosis can be the sole symptom of SLC2OA2-associated IBGC and can be maintained in remission with a low dose of antipsychotics.

SLC20A2 is thought to be the most common causative gene of IBGC [10]. In a study on phenotypes of IBGC, out of 10 patients with $S L C 20 A 2$-associated IBGC, five had cognitive impairment, five had psychiatric symptoms (psychosis $[\mathrm{n}=1]$, mood disorders $[\mathrm{n}=2]$, and others $[\mathrm{n}=2]$ ), five had movement symptoms, and three were asymptomatic [9]. A review reported mood disorders in IBGC had complex syndromes [11]; however, psychosis in IBGC is underrecognized and limited to some case reports (Table 1). Most of the reported cases have a short observational period and are complicated with cognitive impairment or movement disorders [12-18]. Only a few cases [19], including ours, have reported psychiatric symptoms alone. 


\begin{tabular}{|c|c|c|c|c|c|c|c|}
\hline & Sex & $\begin{array}{l}\text { Age at } \\
\text { onset }\end{array}$ & $\begin{array}{l}\text { Psychiatric } \\
\text { symptoms }\end{array}$ & $\begin{array}{l}\text { Movement } \\
\text { disorders }\end{array}$ & $\begin{array}{l}\text { Cognitive } \\
\text { impairment }\end{array}$ & $\begin{array}{l}\text { Region of } \\
\text { calcification }\end{array}$ & Medication per day \\
\hline $\begin{array}{l}\text { Shouyama et al., } \\
2005 \text { [12] }\end{array}$ & Female & 31 & Psychosis & $\begin{array}{l}\text { EPS cerebellar } \\
\text { sign }\end{array}$ & N.A. & B.G. D.N. & $\begin{array}{l}\text { Haloperidol }(8 \mathrm{mg}) \text { à } \\
\text { risperidone }(4 \mathrm{mg})\end{array}$ \\
\hline $\begin{array}{l}\text { Nicolas et al., } \\
2013 \text { [19] }\end{array}$ & Female & 39 & $\begin{array}{l}\text { Psychosis } \\
\text { Depression }\end{array}$ & - & - & B.G. & $\begin{array}{l}\text { Risperidone }(2 \mathrm{mg} \text { ) Venlafaxine } \\
(75 \mathrm{mg})\end{array}$ \\
\hline Pan et al., 2015 [13] & Male & 41 & $\begin{array}{l}\text { Psychosis } \\
\text { obsession }\end{array}$ & $\begin{array}{l}\text { EPS (with } \\
\text { olanzapine [10 } \\
\text { mg]) }\end{array}$ & - & B.G. & $\begin{array}{l}\text { Olanzapine (10 mg a } 2.5 \mathrm{mg} \text { ) } \\
\text { Fluoxetine (20 mg à } 40 \mathrm{mg})\end{array}$ \\
\hline $\begin{array}{l}\text { Younas et al., } \\
2016[14]\end{array}$ & Male & 44 & Psychosis & EPS & + & B.G. & $\begin{array}{l}\text { Donepezil }(10 \mathrm{mg}) \text { à } \\
\text { haloperidol }(2 \mathrm{mg})\end{array}$ \\
\hline $\begin{array}{l}\text { Mohapatra and } \\
\text { Satapathy, } 2016 \text { [15] }\end{array}$ & Male & 55 & Psychosis & EPS & - & B.G. & $\begin{array}{l}\text { Olanzapine }(5 \mathrm{mg}) \text { Procyclidine } \\
(5 \mathrm{mg})\end{array}$ \\
\hline $\begin{array}{l}\text { Naqvi et al., } \\
2017 \text { [16] }\end{array}$ & Male & 18 & Psychosis & Seizure & - & B.G. & $\begin{array}{l}\text { Risperidone }(4 \mathrm{mg}) \\
\text { Procyclidine }(10 \mathrm{mg})\end{array}$ \\
\hline $\begin{array}{l}\text { Levina et al., } \\
2019 \text { [17] }\end{array}$ & Male & 48 & Psychosis & Romberg sign & N.A. & B.G. D.N. & Risperidone (3 mg) \\
\hline $\begin{array}{l}\text { Tololeski et al., } \\
2019 \text { [18] }\end{array}$ & Female & 17 & Psychosis & $\begin{array}{l}\text { EPS } \\
\text { pathological } \\
\text { reflex }\end{array}$ & + & $\begin{array}{l}\text { B.G. } \\
\text { Thalamus }\end{array}$ & $\begin{array}{l}\text { Quetiapine (900 mg) Sertraline } \\
\text { (200 mg) }\end{array}$ \\
\hline The present case & Female & 30 & Psychosis & - & - & B.G. D.N. & Risperidone (1.5 mg) \\
\hline
\end{tabular}

\section{TABLE 1: Summary of previously published IBGC case reports presenting with psychosis}

IBGC cases with psychosis due to a secondary cause were excluded. No published IBGC cases with psychosis reported the causal genetic mutation.

B.G., Basal ganglia; D.N., dentate nuclei; EPS, extrapyramidal symptoms; N.A., not assessed; IBGC, idiopathic basal ganglia calcification.

Classically, IBGC has been classified into two types of psychiatric symptoms: early-onset (median age: 30.7 years) and late-onset (median age: 49.4 years). Early-onset type causes psychosis and is rarely accompanied by movement disorders, whereas late-onset type is associated with dementia and movement disorders; however, these types have not been genetically defined [20]. Our present case is considered to belong to the early-onset type, and we hypothesized that a subgroup of patients with SLC20A2-associated IBGC may present recurrent psychosis.

As our present case indicated, a low dose of antipsychotics can alleviate the symptoms of patients with IBGC without any side effects and should be continued to maintain remission, especially in patients with SLC20A2-associated IBGC. Since no established guidelines are available, medications for psychosis in IBGC patients should be prescribed while considering side effects such as neuroleptic malignant syndrome and extrapyramidal symptoms. Studies have reported the use of risperidone, olanzapine, quetiapine, and haloperidol for psychosis, with relatively small dosages (Table 1 ). In the present case, risperidone (1.5 $\mathrm{mg}$ /day p.o.) maintained remission, and its withdrawal resulted in relapses, thus indicating that the dose was necessary and sufficient. The optimal dose would need to be adjusted for each patient.

Pathophysiologically, SLC20A2 gene encodes PiT-2, which is a type III Na-dependent Pi transporter. Pi level is reported to be elevated in the cerebrospinal fluid of patients with IBGC [8]. Further, it is postulated that the cell calcification mechanism involves the complex formation between extracellular $\mathrm{Pi}$ (high concentrations) and $\mathrm{Ca}^{2+}$ and other metal ions, which causes $\mathrm{Ca}^{2+}$ ions to flow into cells and promote bone differentiation; however, no relationship between the gene mutation site and degree of calcification or clinical phenotype has been established, partly because of insufficient information on the phenotype $[1,9]$. As in our case, longitudinal studies on the genotype-phenotype association are warranted to understand the pathophysiology of IBGC, enable personalized medicine, and predict prognosis, including recurrent clinical course.

\section{Conclusions}

Recurrent psychosis can be the sole symptom of SLC20A2-associated IBGC and can be maintained in 
remission with a low dose of antipsychotics. Literature review including eight case reports shows no superiority between medications. Although our case indicates that a low dose of antipsychotics can alleviate symptoms without any side effects and should be continued to prevent relapse in some patients with IBGC, there has been still shortage of the clinical evidence. Further longitudinal studies on genotype-phenotype associations may expedite personalized medicine for patients with IBGC.

\section{Additional Information \\ Disclosures}

Human subjects: Consent was obtained by all participants in this study. Gifu University and Gifu Pharmaceutical University issued approval 1-26. Written informed consent was obtained from the patient for the case report. The genetic survey on human blood samples was approved by the Ethics Committees of Gifu University and Gifu Pharmaceutical University (Approval number: 1-26) and performed in accordance with Ethical Guidelines for Medical and Health Research Involving Human Subjects in Japan and Ethical Guidelines for Human Genome/Gene Analysis Research in Japan. Conflicts of interest: In compliance with the ICMJE uniform disclosure form, all authors declare the following: Payment/services info: All authors have declared that no financial support was received from any organization for the submitted work. Financial relationships: Hidetaka Tamune declare(s) a grant from Grant-in-Aid for JSPS Fellows. Hidetaka Tamune was supported by Grant-in-Aid for JSPS Fellows Number 20J11742 outside the submitted work. Isao Hozumi declare(s) a grant from Japan Agency for Medical Research and Development. Isao Hozumi was supported (in part) by the Japan Agency for Medical Research and Development (AMED; 18ek0109372h0003) and the Ministry of Health, Labor, and Welfare of Japan (20FC1049). Other relationships: All authors have declared that there are no other relationships or activities that could appear to have influenced the submitted work.

\section{Acknowledgements}

The authors thank Dr. Megumi Yamada for assessing Total Calcification Score (TCS score) and all the staff for their care of the patient and their contributions to this study.

\section{References}

1. Tadic V, Westenberger A, Domingo A, Alvarez-Fischer D, Klein C, Kasten M: Primary familial brain calcification with known gene mutations: a systematic review and challenges of phenotypic characterization. JAMA Neurol. 2015, 72:460-467. 10.1001/jamaneurol.2014.3889

2. Wang C, Li Y, Shi L, et al.: Mutations in SLC20A2 link familial idiopathic basal ganglia calcification with phosphate homeostasis. Nat Genet. 2012, 44:254-256. 10.1038/ng.1077

3. Nicolas G, Pottier C, Maltête D, et al.: Mutation of the PDGFRB gene as a cause of idiopathic basal ganglia calcification. Neurology. 2013, 80:181-187. 10.1212/WNL.0b013e31827ccf34

4. Keller A, Westenberger A, Sobrido MJ, et al.: Mutations in the gene encoding PDGFB cause brain calcifications in humans and mice. Nat Genet. 2013, 45:1077-1082. 10.1038/ng.2723

5. Legati A, Giovannini D, Nicolas G, et al.: Mutations in XPR1 cause primary familial brain calcification associated with altered phosphate export. Nat Genet. 2015, 47:579-581. 10.1038/ng.3289

6. Yao XP, Cheng X, Wang C, et al.: Biallelic mutations in MYORG cause autosomal recessive primary familial brain calcification. Neuron. 2018, 98:1116-1123. 10.1016/j.neuron.2018.05.037

7. Cen Z, Chen Y, Chen S, et al.: Biallelic loss-of-function mutations in JAM2 cause primary familial brain calcification. Brain. 2020, 143:491-502. 10.1093/brain/awz392

8. Nishii K, Shimogawa R, Kurita H, et al.: Partial reduced Pi transport function of PiT-2 might not be sufficient to induce brain calcification of idiopathic basal ganglia calcification. Sci Rep. 2019, 9:1-11. 10.1038/s41598-019-53401-0

9. Nicolas G, Pottier C, Charbonnier C, et al.: Phenotypic spectrum of probable and genetically-confirmed idiopathic basal ganglia calcification. Brain. 2013, 136:3395-3407. 10.1093/brain/awt255

10. Batla A, Tai XY, Schottlaender L, Erro R, Balint B, Bhatia KP: Deconstructing Fahr's disease/syndrome of brain calcification in the era of new genes. Parkinsonism Relat Disord. 2017;37, 1-10. 10.1016/j.parkreldis.2016.12.024

11. Ishitobi M, Kumashiro N, Nakao K: Clinical features of bipolar disorder with idiopathic basal ganglia calcification: a review of case reports in the literature. Neurocase. 2019, 25:145-150. 10.1080/13554794.2019.1638945

12. Shouyama M, Kitabata Y, Kaku T, Shinosaki K: Evaluation of regional cerebral blood flow in fahr disease with schizophrenia-like psychosis: a case report. AJNR Am J Neuroradiol. 2005, 26:2527-2529.

13. Pan B, Liu W, Chen O, Zheng L, Bao Y, Li H, Yu R: Idiopathic basal ganglia calcification presenting as schizophrenia-like psychosis and obsessive-compulsive symptoms: a case report. Exp Ther Med. 2015, 10:608-610. 10.3892/etm.2015.2525

14. Younas S, Malas NM, Abbas D: New-onset psychosis and dementia: an atypical case of Fahr's disease . Prim Care Companion CNS Disord. 2016, 18:10.4088/pcc.15101915

15. Mohapatra S, Satapathy A: A case of schizophrenia like psychosis due to Fahr's disease . Indian J Psychol Med. 2016, 38:155-156. 10.4103/0253-7176.178813

16. Naqvi S, Arshad S, Hanif R, Elfert KAH: Fahr's syndrome misdiagnosed as schizophrenia: a case report. Cureus. 2017, 9:1071. 10.7759/cureus.1071

17. Levina N, Maes F, Sabbe BGC: [Psychosis due to idiopathic basal ganglia calcification]. Tijdschr Psychiatr. 2019, 61:48-52

18. Tololeski BP, Debeljak M, Benedik MP, et al.: The use of quetiapine in treatment of acute psychotic 


\section{Cureus}

symptoms in an adolescent patient with primary brain calcification: a case report. BMC Psychiatry. 2019,

19:67. 10.1186/s12888-019-2047-1

19. Nicolas G, Guillin O, Borden A, Bioux S, Lefaucheur R, Hannequin D: Psychosis revealing familial idiopathic basal ganglia calcification. Gen Hosp Psychiatry. 2013, 35:575-3. 10.1016/j.genhosppsych.2012.09.008

20. Cummings JL, Gosenfeld LF, Houlihan JP, McCaffrey T: Neuropsychiatric disturbances associated with idiopathic calcification of the basal ganglia. Biol Psychiatry. 1983, 18:591-601. 